\title{
Nebulizer Device
}

National Cancer Institute

\section{Source}

National Cancer Institute. Nebulizer Device. NCI Thesaurus. Code C50080.

A device designed to convert a liquid to a mist. 